\title{
A novel matrix for hydrophobic interaction chromatography and its application in lysozyme adsorption
}

\author{
Mehmet Gedikli, Şeyda Ceylan, Mahmut Erzengin ${ }^{\varpi}$ and Mehmet Odabaşı \\ Aksaray University, Faculty of Arts and Science, Department of Chemistry, Aksaray, Turkey
}

\begin{abstract}
A novel 1-naphthylamine (NA) coupled poly(2-hydroxyethyl methacrylate-co- $N$-methacryloyl-(L)-histidine methyl ester) [NA-PHEMAH] supermacroporous monolithic hydrophobic cryogel was prepared via covalent coupling of NA to PHEMAH for adsorption of lysozyme from aqueous solution. Firstly, PHEMAH monolithic cryogel was prepared by radical cryocopolymerization of HEMA with $\mathrm{MAH}$ as a functional comonomer and $N, N^{\prime}$-methylenebisacrylamide (MBAAm) as a crosslinker directly in a plastic syringe, and then NA molecules were covalently attached to the imidazole rings of $\mathrm{MAH}$ groups of the polymeric structure. The prepared, NA-PHEMAH, supermacroporous monolithic hydrophobic cryogel was characterized by scanning electron microscopy (SEM). The effects of initial lysozyme concentration, pH, salt type, temperature and flow rate on the adsorption efficiency of monolithic hydrophobic cryogel were studied in a column system. The maximum amount of lysozyme adsorption from aqueous solution in phosphate buffer was $86.1 \mathrm{mg} / \mathrm{g}$ polymer at $\mathrm{pH} 8.0$ with a flow rate of $1 \mathrm{~mL} /$ min. It was observed that lysozyme could be repeatedly adsorbed and desorbed with the NA-PHEMAH monolithic hydrophobic cryogel without significant loss of the adsorption capacity.
\end{abstract}

Key words: hydrophobic interaction chromatography, lysozyme, 1-naphthylamine, cryogel, PHEMA, SEM

Received: 15 December, 2013; revised: 14 July, 2014; accepted: 03 October, 2014; available on-line: 10 October, 2014

\section{INTRODUCTION}

The separation and purification of proteins has become one of important prerequisites in modern biomedical and pharmaceutical industries ( $\mathrm{Lu}$ et al., 2007). The purity of a protein is an essential prerequisite for its structure and function studies or its potential application (Altintas et al., 2007). The required level of purity depends on the end use of the protein: high degree of purity for structure studies or therapeutic applications, low degree of purity for industrial applications, such as in food industry or domestic detergents (Queiroz et al., 2001). Thus, separation science and technology is a very important area, necessary for further developments in research and technology (Uzun et al., 2005). The selection of a chromatographic technique to perform a given separation will depend on certain biological and physicalchemical properties of the target compounds, such as net charge (ion exchange chromatography), biospecific characteristics (bio-affinity chromatography), and hydro- phobic characteristics (hydrophobic interaction chromatography) (Rojas et al., 2006). In the area of biosciences and biotechnology, a wide variety of protein purification techniques are available today. However, different types of chromatography have become dominant due to their high resolving power (Queiroz et al., 2001; Altintas \& Denizli, 2009). Hydrophobic interaction chromatography (HIC) is a technique used frequently in bioseparations (Altintas et al., 2007; Rojas et al., 2006; Avcibasi et al., 2010; Graumann \& Ebenbichler, 2005; Jungbauer, 2005; Uzun et al., 2004; Denkbas et al., 2002). Chromatography based on hydrophobic interactions was first reported by Shepard and Tiselius, then termed saltingout chromatography (Ueberbacher et al., 2010). HIC has been used to purify antibodies, (Manzke et al., 1997; O'Connor et al., 2000) recombinant proteins, (Kvassman \& Shore, 1995) plasmid DNA (Diogo et al., 1999; Diogo et al., 2000) and virus-like particles (Burdena, 2012). HIC is an important chromatography method for separation of proteins in laboratory scale as well as for production of proteins in industrial scale. Proteins in HIC are adsorbed and separated on the apolar stationary solid phase carrying immobilizied hydrophobic groups. HIC is based on the reversible interaction between the hydrophobic zones of a protein's surface and the hydrophobic ligands of a chromatographic resin. Adsorption in HIC is temperature-dependent and promoted by the salt concentration in the buffer (Ueberbacher et al., 2008). Adsorption is driven by an increase in entropy caused by the release and rearrangement of water molecules that surround hydrophobic patches of the protein and hydrophobic residues on the surface of the adsorbent material (Perkins et al., 2007; Xia et al., 2005).

Lysozyme (N-acetylmuramide glyconohydrolase, (EC 3.2.1.17)) is one of the best characterized hydrolases. Lysozyme, found in a variety of vertebrate cells and secretions, such as spleen, milk, tears and egg white, is a commercially valuable enzyme, and is used for different applications, e.g. as a food additive in milk products, as a cell-disrupting agent for extraction of bacterial intracellular products, as a component of ophthalmologic preparations, and as a drug for treatment of ulcers and infections (Ghosh et al., 2000). High purity requirements for both natural and therapeutic proteins along with the commercial pressures to reduce processing costs have

e-mail: merzengin@hotmail.com

Abbreviations: NA, 1-naphthylamine; MAH, N-methacryloyl-(L)-histidine methyl ester; HEMA, 2-hydroxyethyl methacrylate; PHEMAH, poly(2-hydroxyethyl methacrylate-co- $N$-methacryloyl-(L)-histidine methyl ester); NA-PHEMAH, naphthylamine attached-poly(2-hydroxyethyl methacrylate-co- $N$-methacryloyl-(L)-histidine methyl ester); MBAAm, $N, N^{\prime}$-methylene-bisacrylamide; TEMED, $N, N, N, N^{\prime}$-tetramethylethylenediamine; APS, ammonium persulfate; SEM, scanning electron microscopy; $\mathrm{V}$, volume; TWF, total water fraction. 
stimulated more efficient, simple and relatively less expensive separation techniques for lysozyme production in the recent years (Murakami et al., 1997; Odabasi \& Denizli, 2004). Macroporous cryogel monoliths are considered as a novel generation of stationary phases in the separation and purification of bioproducts such as enzymes, recombinant proteins, viruses and cells in downstream processes. Cryogels have interconnected macropores that are formed in moderately frozen solutions of monomeric and polymeric precursors (Lozinsky et al., 2003; Baydemir \& Odabasi, 2013; Ceylan \& Odabasi, 2013). Solid particulates such as microbial cells or cell debris in the culture fluids are permitted to pass through the cryogel beds freely without blockage (Yao et al., 2006). Several advantages of cryogels are their large pores, short diffusion path, low pressure drop and very short residence time for both adsorption and elution stages (Yilmaz et al., 2009; Erzengin et al., 2011; Unlu et al., 2011).

The aim of this study is to prepare a 1-naphthylamine (NA) coupled supermacroporous monolithic hydrophobic cryogel adsorbent, for adsorption of lysozyme from aqueous solution. The present work was divided into three main parts: firstly, comonomer N-methacryloyl-(L)histidine-methyl ester (MAH) was synthesized, and then, poly(2-hydroxyethyl methacrylate-co- $N$-methacryloyl-(L)histidine-methyl ester) (PHEMAH) monolithic cryogel was prepared by radical cryocopolymerization of HEMA with MAH as a functional comonomer and MBAAm as a crosslinker directly in a plastic syringe, finally, 1-naphthylamine (NA) molecules were covalently attached to the imidazole groups on the MAH to prepare NA-PHEMAH supermacroporous monolithic hydrophobic cryogels columns. The prepared cryogel columns were characterized by scanning electron microscopy (SEM) and swelling tests. Lysozyme adsorption on the NA-PHE$\mathrm{MAH}$ monolithic hydrophobic cryogel from aqueous solutions at different lysozyme concentrations, pHs, temperatures, flow rates and ionic strengths was investigated. Desorption and reusability of NA-PHEMAH monolithic hydrophobic cryogel were also tested.

\section{MATERIALS AND METHODS}

Materials. Lysozyme (chicken egg white, EC 3.2.1.17, molecular mass $14.6 \mathrm{kDa}$ ), L-histidine methyl ester, methacryloyl chloride and 1-naphthylamine were supplied by Sigma (St. Louis, MO, USA). 2-Hydroxyethyl methacrylate (HEMA) obtained from Fluka A.G. (Buchs, Switzerland), distilled under reduced pressure in the presence of hydroquinone inhibitor, and stored at $4^{\circ} \mathrm{C}$ until use. N,N,N,N-tetramethylene daimine (TEMED) was obtained from Fluka A.G. (Buchs, Switzerland). N,N'-methylene-bis-acrylamide (MBAAm) and ammonium persulfate (APS) were supplied by Sigma (St. Louis, MO, USA). All other chemicals were of reagent grade and used as purchased without further purification. All water used in the adsorption experiments was purified using a Barnstead (Dubuque, IA) ROpure LP ${ }^{\circledR}$ reverse osmosis unit with a high-flow cellulose acetate membrane (Barnstead D2731), and then a Barnstead D3804 NANOpure $^{\circledR}$ organic/colloid removal and ion exchange packed-bed system.

Synthesis of MAH monomer. The synthesis and characterization of MAH were performed as described by Denizli and coworkers (2003). Briefly, $5.0 \mathrm{~g}$ of L-histidine methyl ester and $0.2 \mathrm{~g}$ of $\mathrm{NaNO}_{2}$ were dissolved in $30 \mathrm{~mL}$ of $\mathrm{a} \mathrm{K}_{2} \mathrm{CO}_{3}$ aqueous solution $(5 \%, \mathrm{v} / \mathrm{v})$. This solution was cooled to $0^{\circ} \mathrm{C}$. Methacryloyl chloride, 4.0

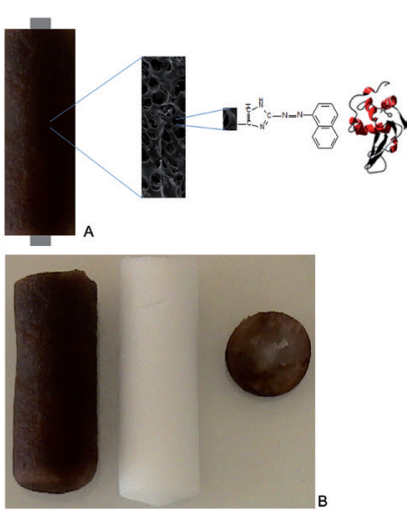

Figure 1. The schematic illustration of NA-coupled PHEMAH cryogel (A) and the optical photograph of plain PHEMAH (white) and NA-PHEMAH cryogels (colored) B.

$\mathrm{mL}$, was poured slowly into this solution under a nitrogen atmosphere and then this solution was stirred magnetically at room temperature for $2 \mathrm{~h}$. At the end of the chemical reaction period, the $\mathrm{pH}$ of this solution was adjusted to 7.0, and then it was extracted with ethyl acetate. The aqueous phase was evaporated in a rotary evaporator. The solid residue (i.e. MAH) was crystallized in ethanol and ethyl acetate.

Preparation of PHEMAH cryogel monoliths. PHEMAH cryogel, is a copolymer of 2-hydroxyethyl methacrylate (HEMA) and $N$-methacryloyl-(L)-histidine methyl ester (MAH), was prepared by bulk polymerization which proceeds in an aqueous solution of monomers frozen inside a glass column (cryo-polymerization). Total concentration of monomers was $6 \%(\mathrm{w} / \mathrm{v})$. The cryogel was produced by free radical polymerization initiated by TEMED $(20 \mu \mathrm{L})$ and APS $(100 \mu \mathrm{L})$. After adding APS $(10 \%(\mathrm{w} / \mathrm{v})$ of the total monomers), the solution was cooled in an ice bath for 2-3 min. TEMED was added and the reaction mixture was stirred for $1 \mathrm{~min}$. Then, the reaction mixture was poured into a plastic syringe $(5 \mathrm{~mL}$, id. $0.8 \mathrm{~cm})$ with closed outled at the bottom. The polymerization solution in the syringe was frozen at $-12^{\circ} \mathrm{C}$ for $24 \mathrm{~h}$, and then thawed at room temperature. Extensive cleaning procedure for removal of unconverted monomers and initiator was performed. Briefly, washing solutions (i.e. a dilute $\mathrm{HCl}$ solution and a water-ethanol mixture) were recirculated through the monolithic cryogel column, until it was certain that the cryogel column is clean.

Preparation of NA-PHEMAH cryogel monoliths. The supermacroporous hydrophobic monolithic cryogel column NA-PHEMAH was prepared by diazotization of 1-naphthylamine (NA) and covalent coupling of it to the PHEMAH cryogel. Briefly, $25 \mathrm{mg}$ of 1 -naphthylamine was completely dissolved in $10 \mathrm{~mL}$ of 1 M HCI solution. $75 \mathrm{mg}$ of $\mathrm{NaNO}_{2}$ dissolved in $5 \mathrm{~mL}$ of cold deionized water was added drop by drop to 1-naphthylamine solution. The reaction was completed by stirring with a magnet for $10 \mathrm{~min}$ in an ice bath. And PHEMAH cryogel was put into this solution. The $\mathrm{pH}$ of solution was adjusted to 9.5 with $1 \mathrm{M} \mathrm{NaOH}$ and, after gentle stirring for 3 hours at room temperature, the brownish NAPHEMAH cryogel was washed with distilled water, and then $0.01 \mathrm{M} \mathrm{Na}_{2} \mathrm{HPO}_{4}$ buffer at $\mathrm{pH}$ 6.0, up to no leakage of brown dye was observed in spectrophotometer. The column was stored in buffer containing $0.02 \%$ sodium azide $+4^{\circ} \mathrm{C}$ until use. The schematic illustration of NA-coupled PHEMAH cryogel for lysozyme adsorption 
(Fig. 1A), and optical photogpaph of plain PHEMAH (White cryogel) and NA-PHEMAH cryogels (colored) are shown in Fig. 1B.

Characterization of cryogel. For the measurement of volume and free water content of the cryogel sample, $\varphi$ value was estimated. A piece of cryogel sample was saturated with deionized water, and then it was immersed in water having volume $V_{1}$; after that, the total volume of cylinder was measured as volume $V_{2}$. Water-saturated cryogel volume, $V_{0}$, was calculated by the volume difference, i.e. $V_{0}=V_{2}-V_{1}$. The mass of water-saturated cryogel, $m_{\mathrm{w}}$, was weighted. After squeezing the cryogel sample to remove the free water within the large pores, the mass of the cryogel sample without free water, $m_{\mathrm{s}}$, was weighted as described previously (Yao et al., 2006). The porosity was calculated by the following formula:

$\varphi=\left(m_{\mathrm{w}}-m_{\mathrm{s}}\right) / \varrho_{\mathrm{w}} V_{0} \times 100$

where $\varrho_{w}$ is the density of deionized water. Then, the cryogel sample was dried in the oven at $60^{\circ} \mathrm{C}$ for $12-$ $24 \mathrm{~h}$ to a constant mass and the dried cryogel mass, $m_{d}$, was determined, and the total water fraction (TWF) was calculated by the following formula:

$\mathrm{TWF}=\left(m_{\mathrm{w}}-m_{d}\right) / \varrho_{\mathrm{w}} V_{0} \times 100$

The morphology of a cross section of the dried NA-PHEMAH cryogel monolith was coated with goldpalladium (40:60) and investigated by SEM (FEI Quanta 250 FEG, Holland).

Lysozyme adsorption studies. The lysozyme adsorption experiments were carried out in a recirculating system equipped with a water jacket for temperature control. The NA-PHEMAH cryogel was washed with $30 \mathrm{~mL}$ of water, and then equilibrated with $0.02 \mathrm{M}$ phosphate buffer containing $0.1 \mathrm{M}\left(\mathrm{NH}_{4}\right)_{2} \mathrm{SO}_{4}$ salt $(\mathrm{pH}$ 8.0). Then, $20 \mathrm{~mL}$ of lysozyme solution was pumped through the column (column volume of $5 \mathrm{~mL}$ ) under recirculation for $1 \mathrm{~h}$ by a peristaltic pump in a continuous system. The adsorption was followed by monitoring of the decrease in UV absorbance at $280 \mathrm{~nm}$. The maximum adsorption capacity of lysozyme on NA-PHEMAH cryogel was estimated according to its adsorption isotherm. Effects of $\mathrm{pH}$ (6.0-11.0), lysozyme concentration $(0.1-3.0 \mathrm{mg} / \mathrm{mL})$, flow rate $(1.0-2.0 \mathrm{~mL} / \mathrm{min})$ and the temperature $\left(5-25^{\circ} \mathrm{C}\right)$ on the adsorption capacity were studied. To observe the effects of salt type on adsorption, buffer solutions including $0.1 \mathrm{M}$ of $\left(\mathrm{NH}_{4}\right)_{2} \mathrm{SO}_{4}$,

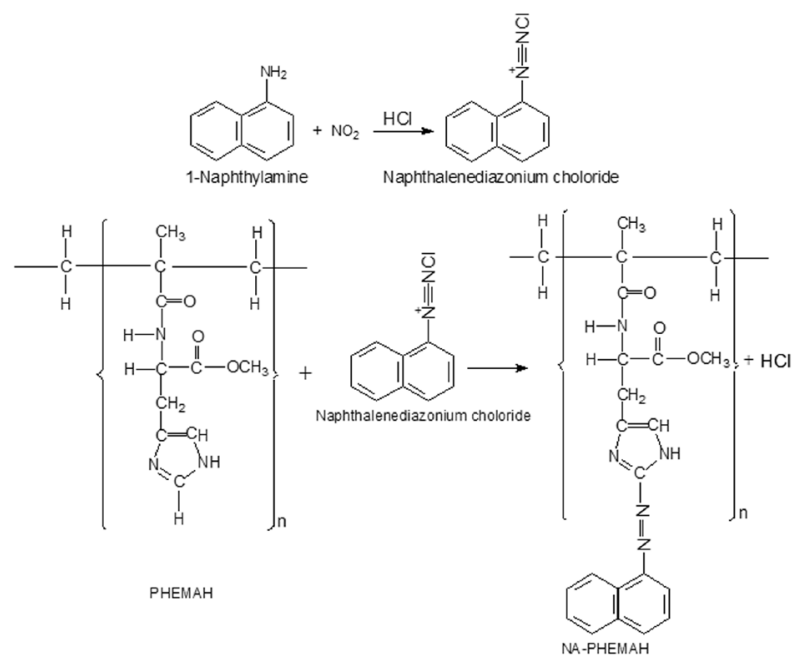

Figure 2. Chemical structure of 1-Naphthylamine coupled PHEMAH monolithic column.
$\mathrm{Na}_{2} \mathrm{SO}_{4}$ and $\mathrm{NaCl}$ were used. All measurements were repeated three times to determine mean values and their standard deviations by the standard statistical method.

Desorption and repeated use. In a typical desorption experiment, $30 \mathrm{~mL}$ of desorption agent was pumped through the cryogel at a flow rate of $1.0 \mathrm{~mL} / \mathrm{min}$ for $30 \mathrm{~min}$. In all cases, lysozyme elution studies were performed using $0.05 \mathrm{M}$ phosphate buffer ( $\mathrm{pH}$ 6.0) containing $0.1 \mathrm{M}$ ethylene glycol solution. The final lysozyme concentration in the desorption medium was determined spectrophotometrically at $280 \mathrm{~nm}$. When desorption was achieved, the NA-PHEMAH cryogel was cleaned with $1 \mathrm{M} \mathrm{NaOH}$ and then re-equilibrated with $0.02 \mathrm{M}$ phosphate buffer containing $0.1 \mathrm{M}\left(\mathrm{NH}_{4}\right)_{2} \mathrm{SO}_{4}$ salt $(\mathrm{pH}$ 8.0). The desorption ratio was calculated from the amount of lysozyme adsorbed on the NA-PHEMAH cryogel and the final lysozyme concentration in the desorption medium. In order to determine the reusability of NA-PHEMAH column, lysozyme adsorption and desorption cycle was repeated 30 times using the same cryogel column.

\section{RESULTS AND DISCUSSION}

\section{Characterization of cryogel}

In this study, we prepared a novel supermacroporous monolithic hydrophobic cryogel [NA-PHEMAH] for adsorption of lysozyme from aqueous solution. Firstly, PHEMAH monolithic cryogel was produced by polymerization in the frozen state of monomers, HEMA and MAH with MBAAm as a cross-linker in the presence of APS/TEMED as an initiator/activator pair, and then, NA molecules were covalently attached to the imidazole groups on the $\mathrm{MAH}$ reactive functional groups

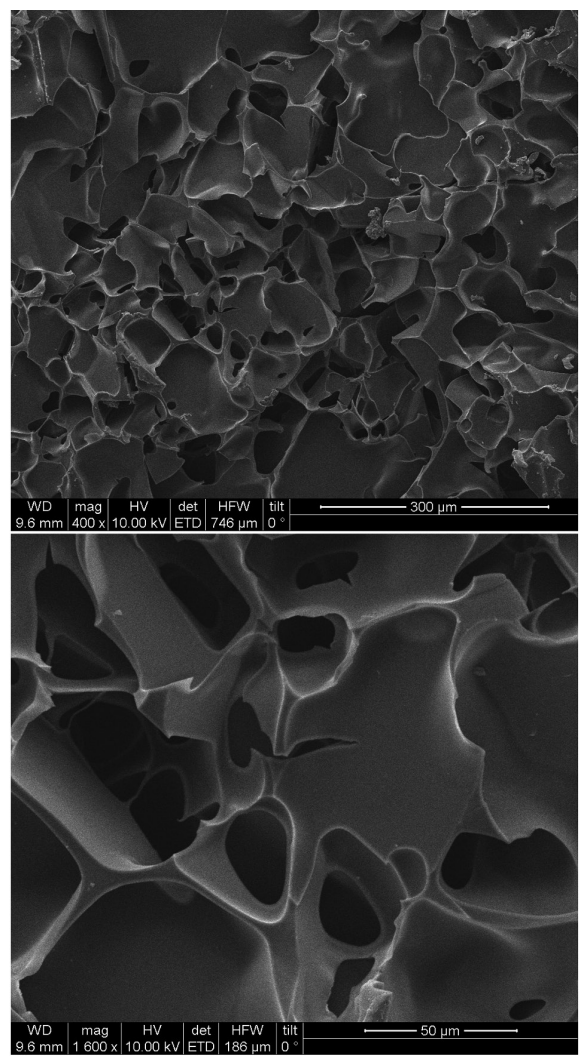

Figure 3. SEM images of the internal structures of the NA-PHEMAH cryogel. 
of the polymeric structure. The chemical structure of newly synthesized NA-PHEMAH monolith was given as Fig. 2. The SEM images of the internal structures of the NA-PHEMAH cryogel are shown in Fig. 3. NA-PHEMAH monolithic cryogel produced in such way have porous and thin polymer walls, large continuous interconnected pores $(10-100 \mu \mathrm{m}$ in diameter) that provide channels for the mobile phase to flow through.

Pore size of the matrix is much larger than the size of the protein molecules, allowing them to pass easily through the pores. Lysozyme is a kind of ovoglobulin with ellipsoidal shape, its size is $4.5 \mathrm{~nm} \times 3 \mathrm{~nm} \times 3$ $\mathrm{nm}$, and a relative molecular weight is 14.300-14.600. As a result of the convective flow of the solution through the pores, the mass transfer resistance is practically negligible. The porosity, $\varphi$, and the total water fraction, TWF, of the NA-PHEMAH cryogel were measured with deionized water as 68.4 and $88.7 \% \mathrm{v} / \mathrm{v}$, respectively. These results indicate that about $20.3 \%$ of the total water was bound by the small pores of polymer matrix where almost no flowing liquid passed through. However, the large pores constituting $68.4 \%$ of the total pores were filled with free water and most of the fluid flow took place within these large pores. On the other hand, the total water content of the NA-PHEMAH cryogel was found lower than the PHEMA cryogel. This result can be explained with hydrophobicity of NA.

\section{Adsorption of lysozyme from aqueous solutions}

\section{Effect of $\mathrm{pH}$}

As shown in Fig. 4, the $\mathrm{pH}$ value of the binding buffer had a great effect on the adsorption of lysozyme. The buffer systems used in this study were prepared with 0.02 $\mathrm{M}$ acetate $(\mathrm{pH}$ 4.0-5.0), $0.02 \mathrm{M}$ phosphate $(\mathrm{pH}$ 6.0-8.0) and $0.02 \mathrm{M}$ carbonate $(\mathrm{pH} 9.0-11.0)$. All the buffers were containing $0.1 \mathrm{M}\left(\mathrm{NH}_{4}\right)_{2} \mathrm{SO}_{4}$. In $\mathrm{pH}$ ranges studied between 6.0-11.0, the excellent adsorption capacities were observed at $\mathrm{pH} 8.0$ as $86.1 \mathrm{mg} / \mathrm{g}$. Below and above this $\mathrm{pH}$, adsorption capacity sharply decreased. This can be explained by electrostatic repulsions between charged groups of lysozyme and NA-PHEMAH croygel matrix. It has been known that in HIC the proteins are adsorbed and separated on the apolar stationary solid phase carrying immobilizied groups. Lysozyme molecule has one histidine, four aspartic acid, two glutamic acid and two tyrosine residues (on the basis of its surface accessible residues). Aromatic side chains of tyrosine amino acid (together with tryptophan and especially phenylalanine) of lysozyme molecules could cause of hydrophobic interaction with the aromatic ring of NA molecules. In addition, NA ligand show a mixed mode behavior where both aromatic and hydrophobic interactions are possible. The aromatic groups of NA have a potential for $\pi-\pi$ interactions. Non-

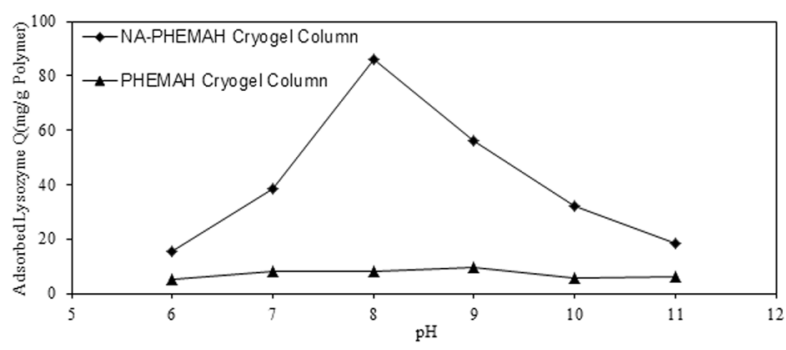

Figure 4. Effect of pH on lysozyme adsorption. Lysozyme concentration: $0.5 \mathrm{mg} / \mathrm{mL}$ in buffer containing $0.1 \mathrm{M}\left(\mathrm{NH}_{4}\right)_{2} \mathrm{SO}_{4}$, flow rate: $1 \mathrm{~mL} / \mathrm{min}, \mathrm{T}: 25^{\circ} \mathrm{C}$.

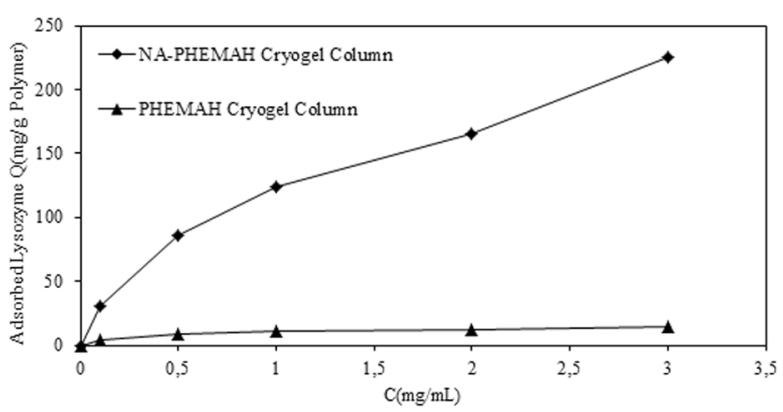

Figure 5. Effect of lysozyme concentration on adsorption. $\mathrm{pH} 8.0$ phosphate buffer containing $0.1 \mathrm{M}\left(\mathrm{NH}_{4}\right)_{2} \mathrm{SO}_{4}$, flow rate: $1 \mathrm{~mL} /$ $\min , \mathrm{T}: 25^{\circ} \mathrm{C}$.

spesific lysozyme adsorption onto plain PHEMAH cryogel was negligible $(8.1 \mathrm{mg} / \mathrm{g})$ at all the $\mathrm{pH}$ ranges studied. This nonspecific adsorption may be due to the diffusion of lysozyme molecules into the swollen cryogel and weak interactions between hydrophilic amino acids of lysozyme surface and PHEMAH cryogel surface.

\section{Effect of initial concentration of lysozyme}

Figure 5 shows the effect of initial lysozyme concentration on adsorption capacity onto the NA-PHEMAH and plain PHEMAH cryogel. The adsorption values increased with increasing concentration of lysozyme, and a saturation value was achieved at lysozyme concentration of $3.0 \mathrm{mg} / \mathrm{mL}$, which represents saturation of the active binding cavities on the NA-PHEMAH cryogel. Maximum adsorption capacity was determined as $225.4 \mathrm{mg} / \mathrm{g}$.

There is a great deal of literature available about different forms of affinity adsorbents for the adsorption and purification of lysozyme from different sources. A comparison of the lysozyme adsorption capacity of different cryogel based hydrophobic affinity adsorbents was given in Table 1 . The maximum lysozyme adsorption that we achieved in this study was $225.4 \mathrm{mg} / \mathrm{g}$, which was quite comparable with the related literature.

\section{Adsorption isotherms}

To evaluate the adsorption properties, modeling of the equilibrium data has been done using the Langmuir and Freundlich isotherms. According to Langmuir adsorption model, molecules are adsorbed at a fixed number of well-defined sites, each of which is capable of holding only one molecule. These sites are also assumed to be energetically equivalent and distant from each other so that there are no interactions between molecules adsorbed on adjacent sites. The Freundlich isotherm describes reversible adsorption and is not restricted to the formation of the monolayer.

The Langmuir adsorption isotherm is shown by Eqn. (3)

$\mathrm{Q}=\mathrm{Q}_{\max } \cdot \mathrm{b} \cdot \mathrm{C}_{\mathrm{eq}} /\left(1+\mathrm{bC}_{\mathrm{eq}}\right)$

where $\mathrm{Q}$ is the adsorbed amount of lysozyme $(\mathrm{mg} / \mathrm{g})$, $\mathrm{C}_{\mathrm{eq}}$ is the equilibrium lysozyme concentration $(\mathrm{mg} / \mathrm{mL})$, $\mathrm{b}$ is the Langmuir constant $\left(\mathrm{mL} / \mathrm{mg}\right.$ ) and, $\mathrm{Q}_{\max }$ is the maximum adsorption capacity $(\mathrm{mg} / \mathrm{g})$. This equation can be linearized so that:

$\mathrm{C}_{\mathrm{eq}} / \mathrm{Q}=1 /\left(\mathrm{Q}_{\max } \mathrm{b}\right)+\mathrm{C}_{\mathrm{eq}} / \mathrm{Q}_{\max }$

The plot of $\mathrm{C}_{\mathrm{eq}}$ versus $\mathrm{C}_{\mathrm{eq}} / \mathrm{Q}$ was employed to generate the intercept of $1 / \mathrm{Q}_{\max } \cdot \mathrm{b}$ and the slope of $1 /$ $\mathrm{Q}_{\max }$. The other well-known isotherm, which is fre- 
Table 1. Comparison of adsorption capacities of different cryogel based hydrophobic adsorbents

\begin{tabular}{llll}
\hline Adsorbent & Ligand & Capacity $(\mathrm{mg} / \mathrm{g})$ & Ref. \\
\hline poly(HEMA-co-DIPPER) & Dipper & 40.9 & Avcibasi et al., 2010 \\
\hline poly(HEMATrp) & MATrp & 46.8 & Yilmaz et al., 2009 \\
\hline poly(HEMA-MAPA) & MAPA & 25.0 & Oncel et al., 2005 \\
\hdashline NA-PHEMAH & NA & 225.4 & This work \\
\hline
\end{tabular}

Table 2. The Langmuir and Freundlich constants for the adsorption of lysozyme on NA- PHEMAH cryogel column

\begin{tabular}{lllllll}
\hline Exp. & Langmuir constants & & \multicolumn{3}{c}{ Freundlich constants } \\
\hline $\begin{array}{l}\mathrm{Q}_{\mathrm{ex}} \\
(\mathrm{mg} / \mathrm{g})\end{array}$ & $\begin{array}{l}\mathrm{Q}_{\max } \\
(\mathrm{mg} / \mathrm{g})\end{array}$ & $\begin{array}{l}\mathrm{b} \\
(\mathrm{ml} / \mathrm{mg})\end{array}$ & $\mathrm{R}^{2}$ & $\mathrm{~K}_{\mathrm{f}}$ & $1 / \mathrm{n}$ & $\mathrm{R}^{2}$ \\
\hdashline 225.4 & 250 & 0.074 & 0.924 & 30.46 & 0.486 & 0.991 \\
\hline
\end{tabular}

quently used to describe adsorption behavior, is the Freundlich isotherm (5):

$\mathrm{Q}=\mathrm{K}_{\mathrm{F}} \cdot \mathrm{C}_{\mathrm{e}}^{1 / \mathrm{n}}(5)$

where $K_{\mathrm{F}}$ is the Freundlich adsorption constant $(\mathrm{mg} / \mathrm{g})$, $\mathrm{Ce}$ is the equilibrium lysozyme concentration $(\mathrm{mg} / \mathrm{mL})$, and $\mathrm{n}$ is the Freundlich exponent which represents the heterogeneity of the system. In Fig. 6 and Table 2, the experimental adsorption behavior was compared with Langmuir and Freundlich adsorption isotherms. According to the correlation coefficients of isotherms, Freundlich adsorption model is applicable to this system.
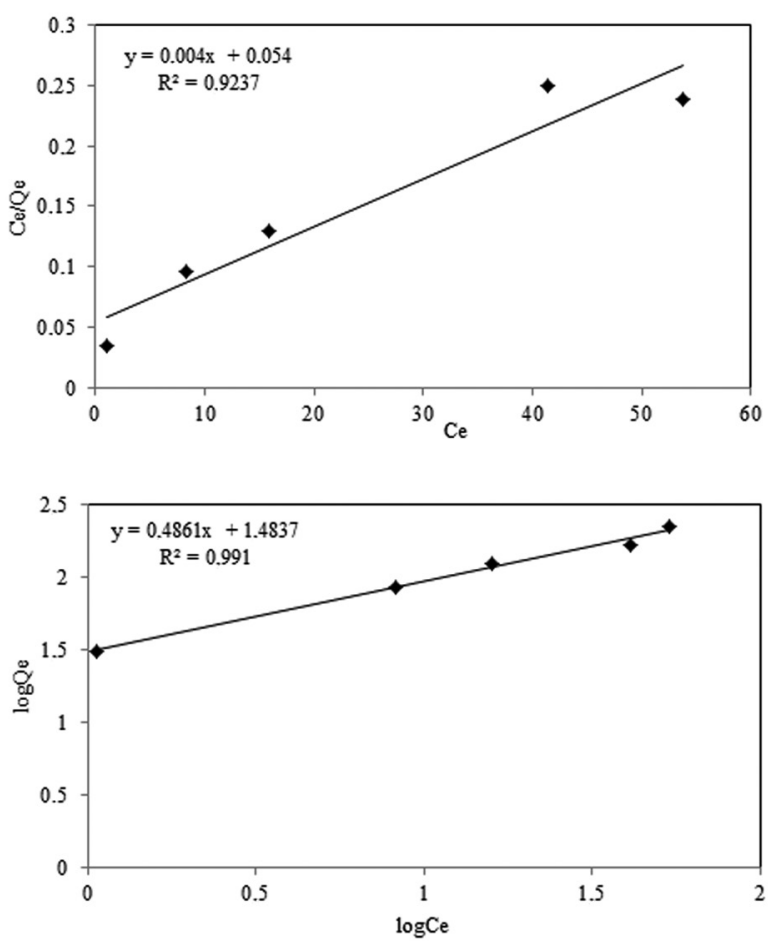

Figure 6. Langmuir (A) and Freundlich (B) adsorption isotherms for lysozyme on NA-PHEMAH cryogel column.
It has been reported that the magnitude of the exponent $1 / \mathrm{n}$ gives an evidence of the favorability and the capacity of the adsorbent system (Huang et al., 2007). If the values of $1 / \mathrm{n}$ is in the range $0.1-1$, the system is shows favourable adsorption. In this study, with the exponent value of 0.486 , the system represents favourable adsorption.

\section{Effect of flow rate}

The flow rate through an affinity chromatography support is an important parameter in generating an optimal separation. Therefore, the amount of lysozyme adsorbed onto the NA-PHEMAH monolithic cryogel at different flow rates was studied. As shown in Figure 7 , the lysozyme adsorption capacity onto the NAPHEMAH cryogel decreases when the flow rate through the column increases. The adsorption capacity decreased significantly from 86.1 to $17.9 \mathrm{mg} / \mathrm{g}$ polymer with the increase of the flow rate from 1.0 to $2.0 \mathrm{~mL} / \mathrm{min}$. An increase in the flow rate reduces the solution volume treated efficiently until breakthrough point and therefore decreases the service time of cryogel column. This is due to decrease in contact time between the lysozyme molecules and NA-PHEMAH monolithic cryogel column at higher flow rates. These results are also in agreement with those referred to the literature (Valdman et al., 2001). When the flow rate decreases the contact time

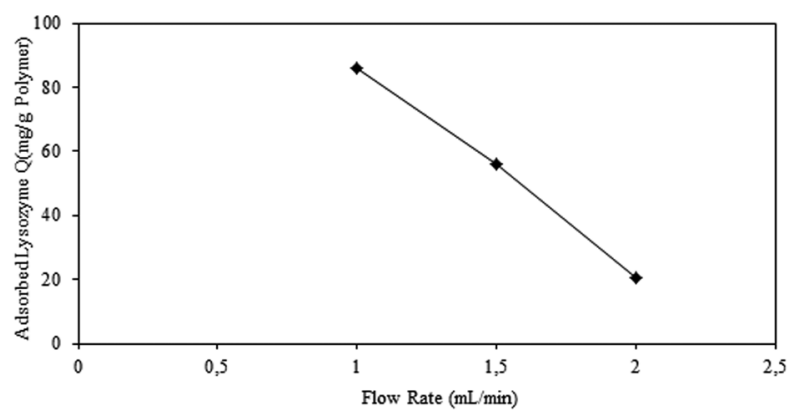

Figure 7. Effect of flow rate on lysozyme adsorption. Lysozyme concentration: $0.5 \mathrm{mg} / \mathrm{mL}$, $\mathrm{pH} 8.0$ phosphate buffer containing $0.1 \mathrm{M}\left(\mathrm{NH}_{4}\right)_{2} \mathrm{SO}_{4}, \mathrm{~T}: 25^{\circ} \mathrm{C}$. 


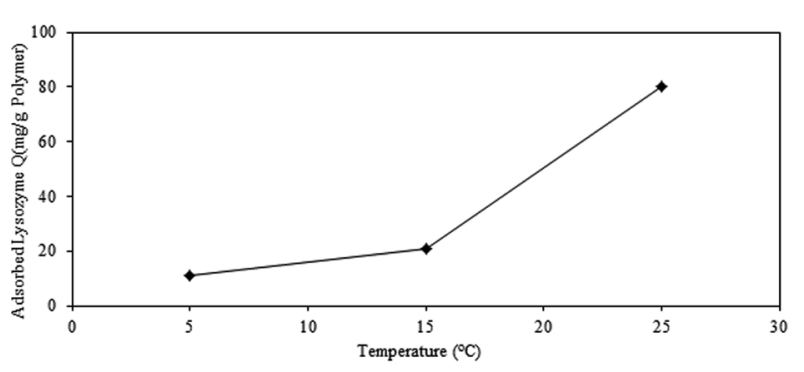

Figure 8. Effect of temperature on lysozyme adsorption. Lysozyme concentration: $0.5 \mathrm{mg} / \mathrm{mL}, \mathrm{pH} 8.0$ phosphate buffer containing $0.1 \mathrm{M}\left(\mathrm{NH}_{4}\right)_{2} \mathrm{SO}_{4}$, flow rate: $1 \mathrm{~mL} / \mathrm{min}$.

in the column is longer. Thus, lysozyme molecules have more time to diffuse to the pore walls of cryogel and to bind to the ligand; hence, a better adsorption capacity is obtained. In addition, for column operation the cryogel is continuously in contact with a fresh protein solution. Consequently, the concentration in the solution in contact with a given layer of cryogel in a column is relatively constant.

\section{Effect of temperature}

Effect of temperature on the adsorption of lysozyme onto the NA-PHEMAH monolithic cryogel is presented in Fig. 8. This study was conducted in the range of $5-25^{\circ} \mathrm{C}$. In hydrophobic interaction chromatography (HIC), increasing the temperature enhances protein retention and lowering the temperature generally promotes the protein elution. Lysozyme adsorption capacity of the NA-PHEMAH cryogel was significantly increased with increasing the temperature up to $25^{\circ} \mathrm{C}$.

\section{Effect of salt type}

In HIC, type and concentration of salt used in the buffer and sample solution influence the ligand-protein interactions and consequently the protein retention. Ammonium sulfate and sodium chloride are the most commonly used salts in HIC applications. In practice, salts such as sodium, potassium or ammonium sulfates are the most effective salts to promote ligand-protein interactions, due to the higher molal surface tension increment effects. For these reason, $\left(\mathrm{NH}_{4}\right)_{2} \mathrm{SO}_{4}, \mathrm{NaCl}$ and $\mathrm{Na}_{2} \mathrm{SO}_{4}$ were used to investigate the effect of salt type on the adsorption capacity. The ionic strength of all the salts studied here were $0.1 \mathrm{M}$. As shown in Fig. 9, the amount of lysozyme adsorbed were 15.30, 35.79, 52.08 and $80.07 \mathrm{mg} / \mathrm{g}$ for no salt condition, $\left(\mathrm{NH}_{4}\right)_{2} \mathrm{SO}_{4}, \mathrm{NaCl}$ and $\mathrm{Na}_{2} \mathrm{SO}_{4}$, respectively.

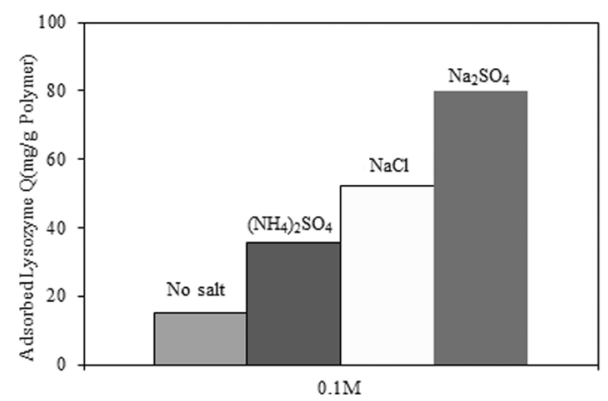

Figure 9. Effect of salt type on lysozyme adsorption capacity of NA-PHEMAH monolithic cryogel. Lysozyme concentration: 0.5 $\mathrm{mg} / \mathrm{mL}, \mathrm{pH} 8.0$ phosphate buffer containing $0.1 \mathrm{M}$ salt, flow rate: $1.0 \mathrm{~mL} / \mathrm{min}, \mathrm{T}: 25^{\circ} \mathrm{C}$

\section{Desorption and reusability studies}

Desorption of lysozyme from NA-PHEMAH monolithic cryogel was also studied in column system. In a typical desorption experiment, $30 \mathrm{~mL}$ of the desorption agent was pumped through the cryogel at a flow rate of $1.0 \mathrm{~mL} / \mathrm{min}$. The final lysozyme concentration in the desorption medium was determined spectrophotometrically at $280 \mathrm{~nm}$. The desorption of lysozyme is expressed in percentage of totally adsorbed lysozyme. Up to $95.1 \%$ of the adsorbed lysozyme was desorbed by using 0.05 $\mathrm{M}$ phosphate buffer ( $\mathrm{pH}$ 6.0) containing 0.1 M ethylene glycol solution. When desorption was achieved, the cryogel was cleaned with $1 \mathrm{M} \mathrm{NaOH}$ and then reequilibrated with 0.02 phosphate buffer containing $0.1 \mathrm{M}$ $\left(\mathrm{NH}_{4}\right)_{2} \mathrm{SO}_{4}$ salt $(\mathrm{pH}$ 8.0). In order to test the reusability of NA-PHEMAH monolithic cryogel, lysozyme adsorption-desorption cycle was repeated for thirty times using the same cryogel column. There was no remarkable reduction in the adsorption capacity of the cryogel. In order to regenerate and sterilize after the desorption, the cryogel was washed with $1 \mathrm{M} \mathrm{NaOH}$ solution.

\section{CONCLUSION}

In this study, 1-naphthylamine (NA) coupled supermacroporous monolithic hydrophobic cryogel adsorbent was prepared for adsorption of lysozyme from aqueous solution. The main advantage of newly synthesized NAPHEMAH cryogel is the fact that it contains covalently attached functional ligand, so there is no risk of ligand leakage into the medium. The maximum lysozyme adsorption was observed at $\mathrm{pH} 8.0$ as $86.1 \mathrm{mg} / \mathrm{g}$. Below and above the maximum adsorption $\mathrm{pHs}$, adsorption capacity decreased significantly. The lysozyme adsorption capacity on NA-PHEMAH cryogel decreased as the flow rate increased. The lysozyme adsorption capacity decreased only $8 \%$ after 30 adsorption-desorption cycles. In recent years, production of cryogels for protein purifications has gained much attention in the area of biochromatography. Biocompatible polymers offer promising potential for exploitation of natural products. Preparing a biocompatible cryogels carrying 1-naphthylamine as a ligand can provide potential benefits for medical, material or cosmetic research areas. It has been shown in this study that NA-PHEMAH hydrophobic monolithic cryogel has good chromatographic properties and is a good candidate for application in the separation of proteins from biological fluids. Moreover, further studies are needed to assess its selectivity.

\section{Declaration of interest}

The authors report no conflicts of interest. The authors alone are responsible for the content and writing of the article.

\section{REFERENCES}

Altintas EB, Denizli A (2009) Monosize magnetic hydrophobic beads for lysozyme purification under magnetic field. Mat Sci Eng C 29: 1627-1634.

Altintas EB, Tuzmen N, Candan N, Denizli A (2007) Use of magnetic poly(glycidyl methacrylate) monosize beads for the purification of lysozyme in batch system. J Chromatogr B 853: 105-113.

Avcibasi N, Uygun M, Corman ME, Akgol S, Denizli A (2010) Application of supermacroporous monolithic hydrophobic cryogel in capturing of albumin. Appl Biochem Biotechnol 162: 2232-2234.

Baydemir G, Odabasi M (2013) Microsphere embedded cryogels for selective and efficient depletion of immunoglobulin $G$ from human serum. Artif Cells Nanomed Biotechnol 41: 319-326. 
Burdena CS, Jin J, Podgornikb A, Bracewell DG (2012) A monolith purification process for virus-like particles from yeast homogenate. J Chromatogr B 880: 82-89.

Ceylan S, Odabasi M (2013) A novel adsorbent for DNA adsorbent: $\mathrm{Fe}^{3+}$-attached sporopollenin embedded composite cryogels. Artif Cells Nanomed Biotechnol 41: 376-383.

Denizli A, Alkan M, Garipcan B, Ozkara S, Piskin E (2003) Novel metal-chelate affinite adsorbent for purification of immunoglobulin$\mathrm{G}$ from human plasma. J Chromatogr B 795: 93-103.

Denkbas EB, Odabasi M, K1lıçay E, Özdemir N (2002) HSA adsorption with chitosan microspheres. I Appl Poly Sci 86: 3035-3039.

Diogo MM, Queiroz JA, Monteiro GA, Martins SAM, Ferreira GNM, Prazeres DMF (2000) Purification of a cystic fibrosis plasmid vector for gene therapy using hydrophobic interaction chromatography. Biotech Bioeng 68: 576-583.

Diogo MM, Queiroz JA, Monteiro GA, Prazeres DMF (1999) Separation and analysis of plasmid denatured forms using hydrophobic interaction chromatography. Anal Biochem 275: 122-124.

Erzengin M, Unlu N, Odabasi M (2011) A novel adsorbent for protein chromatography: supermacroporous monolithic cryogel embedded with $\mathrm{Cu}^{2+}$-attached sporopollenin particles. J Chromatogr A 1218: 484-490.

Ghosh R, Silva SS, Cui ZF (2000) Lysozyme separation by hollow fibre ultrafiltration. Bioch Eng J 6: 19-24.

Graumann K, Ebenbichler AA (2005) Development and scale up of preparative HIC for the purification of a recombinant therapeutic protein. Chem Eng Technol 28: 1398-1407.

Huang J, Liu Y, Jin Q, Wang X, Yang J (2007) Adsorption studies of a water soluble dye, reactive red MF-3B, using sonication-surfactantmodified attapulgite clay. J Haz Mat 143: 541-548.

Jungbauer A (2005) Media for bioseparation. J Chromatogr A 1065 : 3-12.

Kvassman JO, Shore JD (1995) Purification of human plasminogen activator inhibitor (PAI-1) from Escherichia coli and separation of its active and latent forms by hydrophobic interaction chromatography. Fibrinolysis 9: 215-221.

Lozinsky VI, Galaev IY, Plieva FM, Savina IN, Jungvid H, Mattiasson B (2003) Polymeric cryogels as promising materials of biotechnological interest. Trends in Biotechnol 21: 445-451.

Lu AX, Liao XP, Zhou RQ, Shi B (2007) Preparation of Fe(III)-immobilized collagen fiber for lysozyme adsorption. Colloids and Surfaces $A$ 301: 85-93.

Manzke O, Tesch H, Diehl V, Bohlen H (1997) Single-step purification of bispecific monoclonal-antibodies for immunotherapeutic use by hydrophobic interaction chromatography. I Immun Met 208: 65-73.

Murakami F, Sasaki T, Sugahara T (1997) Lysozyme stimulates immunoglobulin production by human-human hybridoma and human peripheral blood lymphocytes. Cytotechnology 24: 177-182.

O'Connor KC, Ghatak S, Stollar BD (2000) Use of hydrophobic interaction chromatography to separate recombinant antibody fragments from associated bacterial chaperone protein GroEL. Anal Biochem 278: 239-241.
Odabasi M, Denizli A (2004) Cibacron blue F3GA incorporated magnetic poly(2-hydroxyethyl methacrylate) beads for lysozyme adsorption. J Appl Poly Sci 93: 719-725.

Oncel S, Uzun L, Garipcan B, Denizli A (2005) Synthesis of phenylalanine-containing hydrophobic beads for lysozyme adsorption. Ind Eng Chem Res 44: 7049-7056.

Queiroz JA, Tomaz CT, Cabral JMS (2001) Hydrophobic interaction chromatography of proteins. J Biotechnol 87: 143-159.

Perkins TW, Mak DS, Root TW, Lightfoot EN (1997) Protein retention in hydrophobic interaction chromatography-modeling variation with buffer ionic-strength and column hydrophobicity. I Chromatogr A 766: 1-14.

Rojas EEG, Coimbra JSR, Minim LA, Saraiva SH, Silva CAS (2006) Hydrophobic interaction adsorption of hen egg white proteins albumin, conalbumin and lysozyme. J Chromatogr B 840: 85-93.

Ueberbacher R, Haimera E, Hahn R, Jungbauer A (2008) Hydrophobic interaction chromatography of proteins V. Quantitative assessment of conformational changes. J Chromatogr A 1198-1199: 154-163.

Ueberbacher R, Rodler A, Hahn R, Jungbauer A (2010) Hydrophobic interaction chromatography of proteins: Thermodynamic analysis of conformational changes. I Chromatogr A 1217: 184-190.

Unlu N, Ceylan S, Erzengin M, Odabasi M (2011) Investigation of protein adsorption performance of $\mathrm{Ni}^{2+}$-attached diatomite particles embedded to composite monolithic cryogels. J Separ Sci 34: 2173-2180.

Uzun L, Odabaşı M, Arıca Y, Denizli A (2004) Poly(styrene-hydroxyethyl methacrylate) monodisperse microspheres as specific sorbent in dye affinity adsorption of albumin. Sep Sci Technol 39: 2401-2418.

Uzun L, Say R, Denizli A (2005) Porous poly ( hydroxyethyl methacrylate-N-methacryloyl-(L)-histidinemethylester ) based monolith as a new adsorbent for affinity chromatography. React Func Poly 64: 93-102.

Xia F, Nagrath D, Cramer SM (2005) Effect of $\mathrm{pH}$ changes on water release values in hydrophobic interaction chromatographic systems. J Chromatogr A 1079: 229-235.

Valdman E, Erijman L, Pessoa FLP, Leite SGF (2001) Continuous biosorption of $\mathrm{Cu}$ and $\mathrm{Zn}$ by immobilized waste biomass Sargassum sp. Process Biochem 36: 869-873.

Yao K, Shen S, Yun J, Wang L, He X, Yu X (2006) Preparation of polyacrylamide-based supermacroporous monolithic cryogel beds under freezing-temperature variation conditions. Chem Eng Sci 61: 6701-6708.

Yao K, Yun J, Shen S, Wang L, He X, Yu X (2006) Characterization of a novel continuous supermacroporous monolithic cryogel embedded with nanoparticles for protein chromatography. J Chromatogr A 1109: 103-110.

Yilmaz F, Bereli N, Yavuz H, Denizli A (2009) Supermacroporous hydrophobic affinity cryogels for protein chromatography. Biochem Eng J 43: 272-279. 